\title{
Spontaneous direct bonding of thick silicon nitride
}

\section{S Sánchez $\dagger, C$ Gui and M Elwenspoek}

MESA Research Institute, University of Twente, PO Box 217, 7500 AE Enschede, The Netherlands

Presented on 21 October 1996, accepted for publication on 7 April 1997

\begin{abstract}
Wafers with $1 \mu \mathrm{m}$ LPCVD silicon-rich nitride layers have been successfully direct bonded to silicon-rich nitride and boron-doped silicon surfaces. A chemical-mechanical polishing treatment was necessary to reduce the surface roughness of the nitride before bonding. The measured surface energies of the room-temperature bond were comparable to values found for Si-Si hydrophilic bonding. A mechanism similar to this bonding is suggested for silicon nitride bonding.
\end{abstract}

\section{Introduction}

Direct bonding of LPCVD $\mathrm{Si}_{x} \mathrm{~N}_{y}$ has been presented in several papers $[1,2]$, but these works involved silicon nitride layers of a thickness of $140 \mathrm{~nm}$ or less. Direct bonding of $\mathrm{Si}_{x} \mathrm{~N}_{y}$ layers with a thickness of $1 \mu \mathrm{m}$ or more is nearly impossible because of the large surface roughness of such a layer.

Silicon nitride bonding is an interesting technology for the production of a high- $T_{c}$ superconductor bolometer, where bonding of $\mathrm{Si}_{x} \mathrm{~N}_{y}$ to $\mathrm{Si}$ is used to obtain a thin singlecrystal Si layer on top of a silicon nitride membrane $[3,4]$. The use of chemical-mechanical polishing (CMP) for the reduction of the surface roughness shows its importance in silicon wafer bonding [5].

\section{Wafer preparation}

For the bonding experiments, $380 \mu \mathrm{m}$ thick $3^{\prime \prime}$ (100) $\mathrm{Si}$ wafers were selected, having a curvature of less than $10 \mu \mathrm{m}$ across $50 \mathrm{~mm}$. The used silicon nitride layers were $1 \mu \mathrm{m}$ thick low-stress LPCVD grown $\mathrm{Si}_{x} \mathrm{~N}_{y}$. Boron implantation was done at $200 \mathrm{keV}$, with a concentration of $2 \times 10^{16} \mathrm{~cm}^{-2}$, followed by a $30 \mathrm{~min}$ anneal at $960^{\circ} \mathrm{C}$. Boron dotation in a solid source dotation (SSD) system was done at $1150^{\circ} \mathrm{C}$, leaving a surface concentration of $3 \times 10^{20} \mathrm{~cm}^{-3}$.

The nitride wafers were given a CMP treatment in order to reduce the surface roughness from 2.9 to 0.3 $\mathrm{nm}\left(R_{a}\right.$ value, calculated from a $20 \times 20 \mu \mathrm{m}^{2}$ atomic force microscope (AMF) scan). An AFM scan of a $\mathrm{Si}_{x} \mathrm{~N}_{y}$ surface before and after CMP is shown in figure 1. Besides reducing the 'natural' surface roughness of the thick silicon nitride, CMP also removed particle contaminations induced by the LPCVD silicon nitride growth process. These particles are typically up to $80-100 \mathrm{~nm}$ in diameter. To obtain a good bondable surface an overall amount between

\footnotetext{
$\dagger$ Tel: +31 53489 4435. Fax +31 53 4893343. E-mail address: s.sanchez@el.utwente.nl
}

30 and $50 \mathrm{~nm}$ of $\mathrm{Si}_{x} \mathrm{~N}_{y}$ was removed with CMP, with a removal rate of $2-3 \mathrm{~nm} / \mathrm{min}$.

The boron-implanted wafers were used without CMP. After removing the thin oxide layer which is used to prevent channelling, the surface roughness is comparable to that of a CMP treated wafer. Before further processing, all polished wafers were cleaned in a $\mathrm{H}_{2} \mathrm{SO}_{4} / \mathrm{H}_{2} \mathrm{O}_{2} / \mathrm{H}_{2} \mathrm{O}$ 1:1:5 solution at $80^{\circ} \mathrm{C}$, removing the polishing slurry contaminants.

\section{Bonding process}

Prior to bonding, the wafers were cleaned with fuming nitric acid $(100 \%)$ and hot nitric acid $\left(70 \%\right.$ at $\left.90^{\circ} \mathrm{C}\right)$, followed by a quick dump rinse (QDR) with DI water. The wafers were kept wet in the QDR, rinsing several times, and spin dried only just before bonding. To speed up the bonding process a small pressure was applied until bonding initiated. Two wafer pairs were put in a 5\% HF solution for $1 \mathrm{~min}$ to investigate the influence of the chemical oxi-nitride layer which is left after cleaning. An IR camera was used to monitor the initial bonding of the wafers. Annealing was done for $2 \mathrm{~h}$ at 800,900 or $1000^{\circ} \mathrm{C}$ in $\mathrm{N}_{2}$ or $\mathrm{O}_{2}$.

\section{Results}

Using the described wafer preparation we have achieved spontaneous room-temperature bonding of $\mathrm{Si}_{x} \mathrm{~N}_{y}$ to $\mathrm{Si}_{x} \mathrm{~N}_{y}$, boron-implanted and SSD doped Si. The speed of the bondwave was measured to be up to $3 \mathrm{~cm} \mathrm{~s}^{-1}$. IR images of a typical propagating bondwave between $\mathrm{Si}_{x} \mathrm{~N}_{y}$ and boronimplanted $\mathrm{Si}$ are shown in figure 2.

The bond strength of the room-temperature bond was measured with the crack propagation method [6]. The values for the surface energy of the room-temperature bond are given in table 1 . The values for the $\mathrm{Si}_{x} \mathrm{~N}_{y}$ to $\mathrm{Si}_{x} \mathrm{~N}_{y}$ bond are in the same range as for $\mathrm{Si}-\mathrm{Si}$ hydrophilic bonds [7]. The use of an HF dip resulted in a weaker room-temperature bond, and also in a weaker bond after annealing. However, 

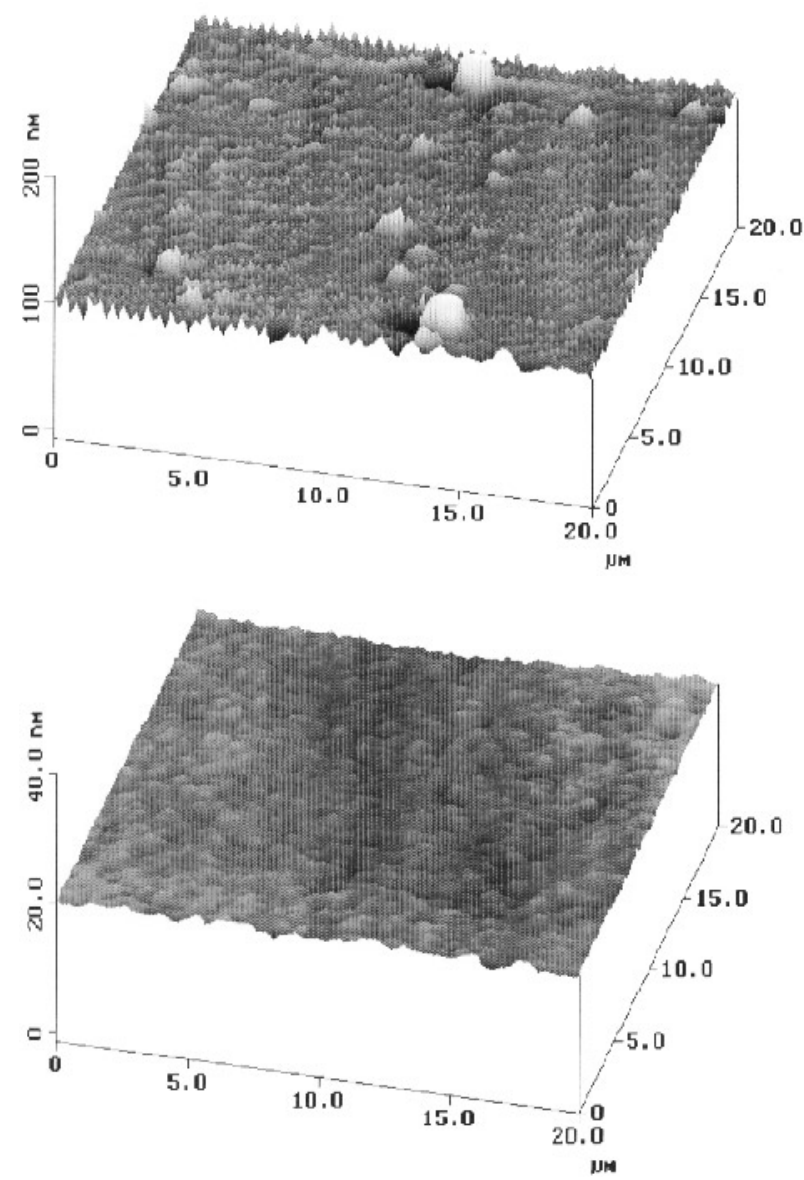

Figure 1. AFM images of LPCVD $\mathrm{Si}_{x} \mathrm{~N}_{y}$ surfaces before (top) and after (bottom) CMP; the $R_{a}$ roughnesses are 2.9 $\mathrm{nm}$ and $0.3 \mathrm{~nm}$ respectively.

Table 1. Surface energies of room-temperature bonds of different bonded surfaces.

\begin{tabular}{ll}
\hline Bonded surface & Surface energy $\left(\mathrm{J} \mathrm{m}^{-2}\right)$ \\
\hline $\mathrm{Si}_{x} \mathrm{~N}_{y}-\mathrm{Si}_{x} \mathrm{~N}_{y}$ & $0.08-0.16$ \\
$\mathrm{Si}_{x} \mathrm{~N}_{y}-\mathrm{Si}_{x} \mathrm{~N}_{y}$ with HF & $0.01-0.04$ \\
$\mathrm{Si}_{x} \mathrm{~N}_{y}-\mathrm{B}$-implanted $\mathrm{Si}$ & $0.12-0.29$ \\
\hline
\end{tabular}

it should be noted that the HF dip before bonding was only performed once. On one measured sample the surface energy of the $\mathrm{Si}_{x} \mathrm{~N}_{y}$ to $\mathrm{Si}_{x} \mathrm{~N}_{y}$ bond after annealing at $1000{ }^{\circ} \mathrm{C}$ for $2 \mathrm{~h}$ was between 1.1 and $2.8 \mathrm{~J} \mathrm{~m}^{-2}$.

\section{Silicon-on-nitride}

Using a bond-and-etch-back technology, silicon-on-nitride (SON) layers were produced (figure 3). Etching was done using the boron etch stop in KOH/IPA. After reaching the boron layer, the $\mathrm{Si}$ top layer was given a short CMP step to both reduce the thickness and the surface roughness. A Si top layer of $300 \pm 50 \mathrm{~nm}$ was made this way, which at this moment seems to be best obtainable result using a single etch stop. These layers will be used for the production of a high- $T_{c}$ superconductor bolometer [3, 4]. In recent experiments successful bonding was achieved between commercially obtained 4 " SOI wafers from AT\&T
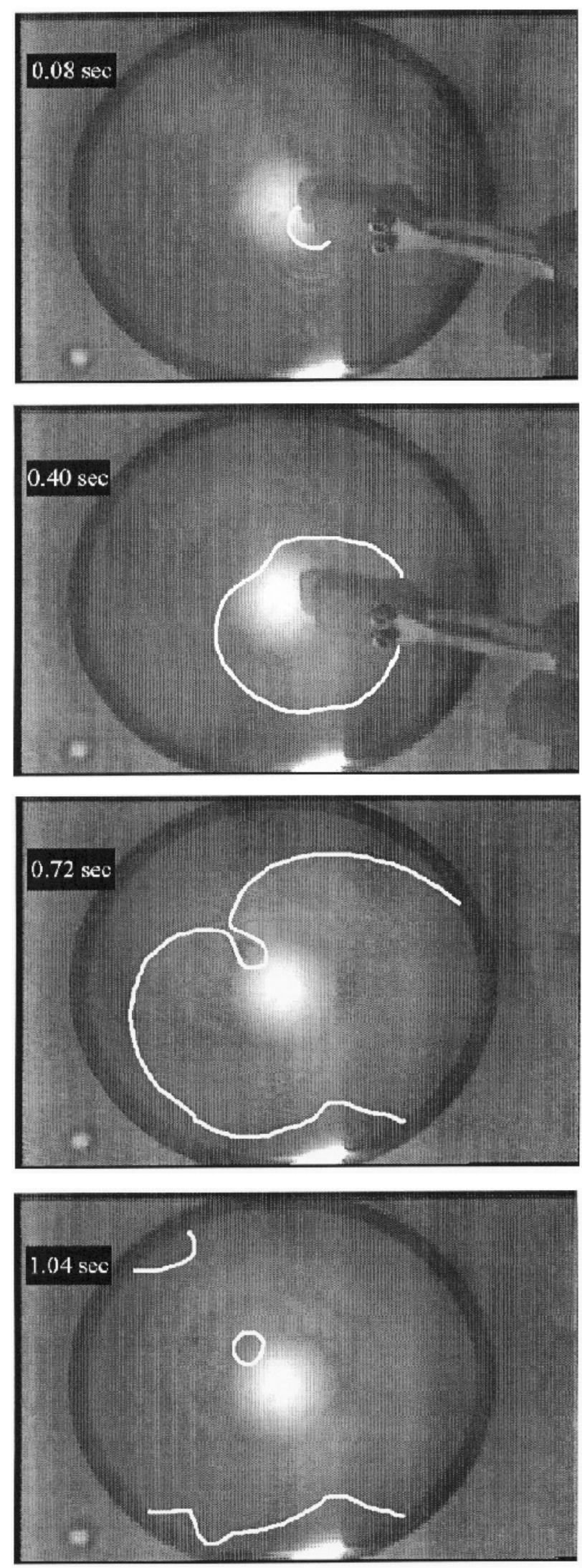

Figure 2. IR images showing the bondwave between LPCVD $\mathrm{Si}_{x} \mathrm{~N}_{y}$ and boron-implanted $\mathrm{Si}$, initiated at the center of the 3 inch wafer; the front of the propagating bondwave has been marked because of the poor contrast in the pictures.

and $4^{\prime \prime}$ wafers with a $1 \mu \mathrm{m} \mathrm{Si}_{x} \mathrm{~N}_{y}$ layer (after a CMP treatment). The $\mathrm{Si}$ top layer of the SOI wafer was 


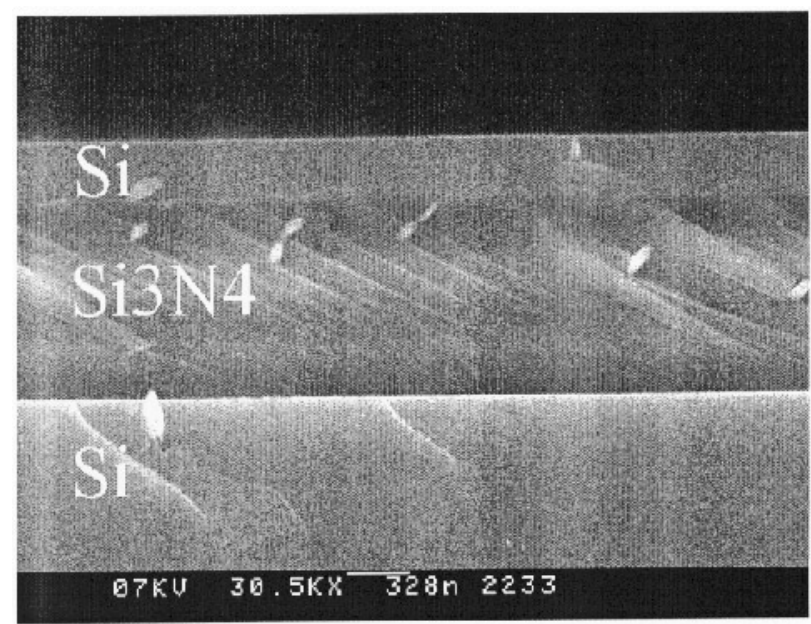

Figure 3. SEM photograph of a $0.4 \mu \mathrm{m}$ Si layer on top of a $1 \mu \mathrm{m} \mathrm{Si} \mathrm{N}_{y}$ layer using an implanted $\mathrm{p}^{++}$layer.

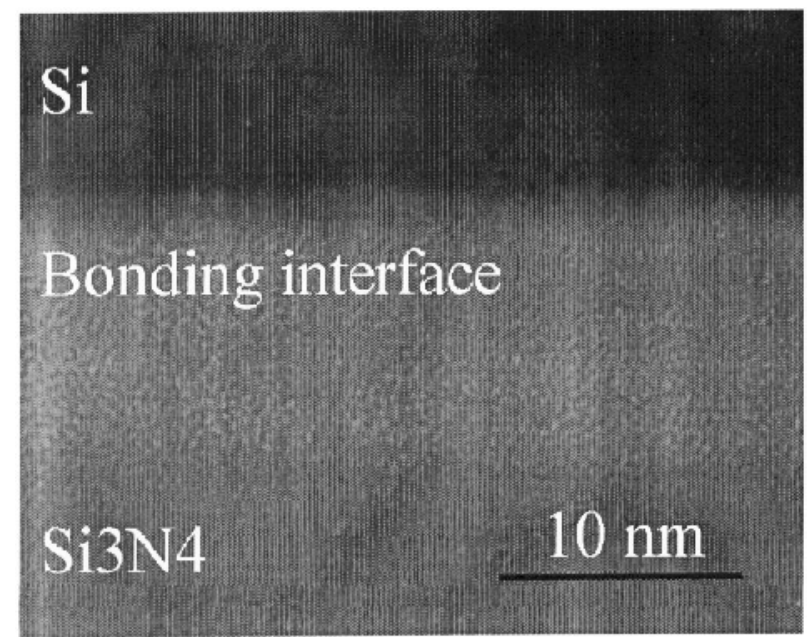

Figure 4. TEM image showing the bonding interface between boron-doped $\mathrm{Si}$ to $\mathrm{Si}_{x} \mathrm{~N}_{y}$.

successfully transferred to the nitride wafer by bonding and etch-back. Because of the double etch stop in the SOI wafer, this route increases the thickness uniformity of the Si top layer of the obtained SON layer, which is only dependent on the SOI wafer specifications.

\section{Discussion}

After a standard cleaning process, the $\mathrm{Si}_{x} \mathrm{~N}_{y}$ surface is covered with a thin hydrophilic chemical silicon oxi-nitride layer. Therefore we suggest that the bonding mechanism of $\mathrm{Si}_{x} \mathrm{~N}_{y}-\mathrm{Si}_{x} \mathrm{~N}_{y}$ is comparable to $\mathrm{Si}-\mathrm{Si}$ bonding, where bonding actually occurs between the two thin native oxide layers [8]. Using the same bonding procedure, $\mathrm{Si}-\mathrm{Si}$ bonding resulted in a $2.7 \mathrm{~nm}$ thick bonding interface. Bonding of $\mathrm{Si}_{x} \mathrm{~N}_{y}$ to $\mathrm{Si}$ left a $8-10 \mathrm{~nm}$ thick amorphous interface (figure 4), whose exact chemical composition is still under investigation.

An unsolved problem is the presence of small voids (containing gas) and unbonded areas in the bonding interface. They have a typical diameter between 50 and
$400 \mu \mathrm{m}$, and appear particularly towards the edge of the bonded wafer pair. We believe that they are the result of remaining surface microroughness on the $\mathrm{Si}_{x} \mathrm{~N}_{y}$ surface, rather than just a result of the reaction at the interface during annealing. After the CMP treatment, the surface roughness of the $\mathrm{Si}_{x} \mathrm{~N}_{y}$ layer is probably somewhat higher towards the edge of the wafer. A model is currently being developed where the influence of the microroughness on the bondability is expressed as an adhesion parameter [9]. This model also takes into account the Young's moduli of the bonded materials. This might explain the higher surface energies found for the $\mathrm{Si}_{x} \mathrm{~N}_{y}-\mathrm{Si}$ bond, since the Young's modulus for $\mathrm{Si}$ is about a factor of two lower than for $\mathrm{Si}_{x} \mathrm{~N}_{y}$.

When making the SON layers, an additional annealing step was used following the etch-back process. After thinning the Si top layer to about $0.6 \mu \mathrm{m}$, a $4 \mathrm{~h}$ anneal at $1000^{\circ} \mathrm{C}$ was given, which significantly reduced the unbonded areas of the still intact Si top layer.

\section{Conclusion}

We have successfully bonded thick silicon nitride to silicon nitride, a boron-implanted Si surface and a SSD boron Si surface. This was only possible after CMP of silicon nitride in order to reduce the surface roughness. This process was used to produce silicon-on-nitride layers for bolometric applications.

\section{Acknowledgments}

The high- $T_{c}$ bolometer project is funded by the European Space Agency under contract no $11738 / 95 / \mathrm{NL} / \mathrm{PB}$, and is being carried out with SRON Utrecht (The Netherlands), IHT Hannover and IPHT Jena (both in Germany). The contract manager is Dr E Armandillo.

\section{References}

[1] Bower R W, Ismail M S and Roberts B E 1993 Low temperature $\mathrm{Si}_{3} \mathrm{~N}_{4}$ direct bonding Appl. Phys. Lett. 62 3485

[2] Harendt C, Graf H-G, Höfflinger B and Penteker E 1992 Silicon fusion bonding and its characterizations J. Micromech. Microeng. 2113

[3] Sánchez S et al 1996 A high- $T_{c}$ superconductor bolometer on a $\mathrm{Si}_{3} \mathrm{~N}_{4} / \mathrm{Si}$ membrane Proc. National Sensor Conference (Delft, The Netherlands) 20-21 March 1996 pp 99-102

[4] de Nivelle $\mathrm{M}$ et al $1996 \mathrm{~A}$ high- $T_{c}$ superconductor bolometer for remote sensing of atmospheric $\mathrm{OH}$ J. Physique Coll. IV C3-423

[5] Gui C, Gardeniers J G E, Elwenspoek M, Albers H and Lambeck P V 1996 Silicon fusion bonding with chemical mechanical polishing Proc. National Sensor Conference (Delft, The Netherlands) 20-21 March 1996 pp 93-7

[6] Maszara W P, Goetz G, Caviglia A and McKitterick J B 1995 Bonding of silicon wafers for silicon-on-insulator J. Appl. Phys. 644943

[7] Ljungberg K 1995 Phenomenology of silicon wafer bonding PhD Thesis Uppsala University p 21

[8] Stengl R, Tan T and Gösele U 1989 A model for the silicon wafer bonding process Japan. J. Appl. Phys. 281735

[9] Gui C to be published 